\title{
ALEITAMENTO MATERNO NO SISTEMA PENITENCIÁRIO: SENTIMENTOS DA LACTANTE
}

\section{Breastfeeding in the penitentiary system: infant's feelings}

Lactancia materna en el sistema penitenciario: sentimientos de la mujer lactante

Angelita Nogueira Medeiros • Centro de Oncologia da Unimed/Caruaru-PE • Enfermeira • Especialista em Oncologia e Cuidados Paliativos •

E-mail: enfa.angelitamedeiros@gmail.com

Bruna Mariane Vasconcelos Ferreira - Unidade de Pronto Atendimento e de Atenção Especializada/UPAE Caruaru-PE • Enfermeira • Especialista em Gestão em saúde e controle de infecção • E-mail: brunavasconcelos1305@gmail.com Luana Vanessa Ferreira de Azevedo Costa • Enfermeira da Estratégia de Saúde da Família/Garanhuns-PE • Especialista em UTI com ênfase em gestão/Faculdade IDE - Docente em Centro Técnico Pernambucano/Garanhuns-PE • E-mail: luana.acosta@hotmail.com Júlio César Bernardino da Silva • Secretaria de Saúde do Recife/SESAU • Enfermeiro $\bullet$ Residente em Enfermagem Obstétrica $\bullet$ Participante do Instituto de Estudos Avançados do Centro Universitário Tabosa de Almeida/ ASCES-UNITA • E-mail: cesarsilva04@hotmail.com

Marilia Cruz Gouveia Câmara Guerra • Centro Universitário Tabosa de Almeida/ASCES-UNITA • Enfermeira $\bullet$ Mestrado em Enfermagem pela Universidade Federal de Pernambuco/UFPE • Docente do Centro Universitário Tabosa de Almeida/ASCES-UNITA • E-mail: mariliacamara@asces.edu.br Nayale Lucinda Andrade Albuquerque • Enfermeira $\bullet$ Doutoranda em Saúde Integral do Instituto de Medicina Integral Professor Fernando Figueira - IMIP • Docente e Pesquisadora do Instituto de Estudos Avançados do Centro Universitário Tabosa de Almeida/ASCES-UNITA • E-mail: nayalealbuquerque@asces.edu.br

Autora responsável pela correspondência:

Angelita Nogueira • E-mail: enfa.angelitamedeiros@gmail.com 


\section{RESUMO}

Introdução: $O$ direito à amamentação é inerente à mulher em qualquer circunstância, inclusive àquelas que estão em privação de liberdade. Para que esse direito seja garantido, existe a base jurídico-constitucional que valoriza a efetividade dessa ação, mesmo que a realidade se mostre incoerente quanto à garantia das especificidades acerca da digna amamentação no cárcere. Objetivo: Compreender os sentimentos das lactantes em situação prisional acerca da amamentação. Método: Estudo descritivo, exploratório, qualitativo, realizado com 08 lactantes reclusas na Colônia Penal Feminina Bom Pastor, no município de Recife, capital de Pernambuco. Foram realizadas entrevistas semiestruturadas, guiadas pela questão norteadora: Como mãe, quais os sentimentos de amamentar seu(a) filho(a) na prisão? As falas foram submetidas à análise de conteúdo temática proposta por Bardin e representada seus resultados a partir de categorias. Resultados: A partir da análise dos discursos emergiram as seguintes categorias: Amamentação: meio de prevenção de doenças e de cumprimento do papel de mãe; Desmame precoce no ambiente prisional e processo de separação mãe e filho: dicotomia de sentimentos positivos e negativos e a experiência do amamentar no ambiente prisional e sua correlação com o extramuros. Conclusões: Inúmeros são os sentimentos vivenciados pelas lactantes permeando os extremos de prazer, amor e tristeza e culpa, sendo estes últimos conseguinte a separação da criança completos os seis meses. A ausência de orientações advindas dos profissionais de saúde acentua as dificuldades das mulheres frente ao aleitamento materno.

Palavras-Chave: Aleitamento Materno; Sentimentos; Presídio.

\section{ABSTRACT}

Introduction: The right to breastfeeding is inherent in women under all circumstances, including those deprived of their liberty. For this right to be guaranteed, there is the legal-constitutional basis that values the effectiveness of this action, even if the reality proves to be inconsistent as to the guarantee of the specifics about decent breastfeeding in prison. Objective: Understand the feelings of the infants in prisons about breastfeeding. Methods: A descriptive, exploratory, qualitative study was carried out with eight reintegrated infants in the Bom Pastor Feminine Penal Colony, in the city of Recife, capital of Pernambuco. Semi-structured interviews were conducted, guided by the guiding question: As a mother, what are the feelings of breastfeeding your child in prison? The speeches were submitted to the thematic content analysis proposed Bardin and represented his results from of categories. Results: From the scourse analysis the following categories emerged: Breastfeeding: a means of eventing diseases and fulfilling the role of mother; Early weaning in the prison vironment and separation process mother and child: dichotomy of positive 
and negative feelings and the experience of breastfeeding in the prison environment and its correlation with the outside walls. Conclusions: Many feelings are experienced by infants permeating the extremes of pleasure, love and sadness and guilt, the latter being the separation of the child complete six months. The lack of guidance from health professionals accentuates women's difficulties with breastfeeding.

Keywords: Breastfeeding; Feelings; Prison.

\section{RESUMEN}

Introducción: El derecho a la lactancia materna es inherente a las mujeres en todas las circunstancias, incluidas las privadas de libertad. Para garantizar este derecho, existe la base legal-constitucional que valora la efectividad de esta acción, incluso si la realidad resulta ser inconsistente en cuanto a la garantía de los detalles sobre la lactancia materna decente en prisión. Objetivo: Comprender los sentimientos de las mujeres que amamantan en prisión sobre la lactancia materna. Método: Estudio descriptivo, exploratorio, cualitativo, realizado con 08 reclusas lactantes en la Colonia Penal Femenina Bom Pastor, en la ciudad de Recife, capital de Pernambuco. Se realizaron entrevistas semiestructuradas, guiadas por la pregunta guía: ¿Cómo se siente la madre al amamantar a su hijo en la cárcel? Los discursos se sometieron al análisis de contenido temático propuesto por Bardin y representaron sus resultados de de categorías. Resultados: Del análisis del discurso, surgieron las siguientes categorías: Lactancia materna: medios de prevención de enfermedades y cumplimiento del papel de la madre; Destete temprano en el ambiente carcelario y el proceso de separación entre madre e hijo: dicotomía de sentimientos positivos y negativos y la experiencia de la lactancia materna en el ambiente carcelario y su correlación con extramuros. Conclusiones: Hay innumerables sentimientos experimentados por las mujeres que amamantan que impregnan los extremos de placer, amor, tristeza y culpa, siendo esta última la separación del niño completo a los seis meses. La falta de orientación de los profesionales de la salud acentúa las dificultades de las mujeres que se enfrentan a la lactancia materna.

Palabras Clave: Lactancia Materna; Sentimiento; Prisión.

\section{Introdução}

A alimentação adequada das crianças começa com o leite materno. A mamentação regular oferece um potencial de ampla proteção ao organismo umano desde a tenra idade e por toda a vida, prevenindo doenças durante a fância, que pode se prolongar pela vida adulta ${ }^{1}$. 
O leite humano contém antioxidantes, hormônios e fatores de crescimento, com atividade biológica relacionada ao desenvolvimento, à regulação metabólica e à inflamação. Tal combinação produz efeitos protetores à saúde dos lactentes ${ }^{1}$.

A amamentação é uma prática que ao longo dos anos sofreu influências sociais, econômicas e culturais em decorrência da incorporação de costumes pela sociedade, então o ato de amamentar está interligado a nutriz e a sua rede social ${ }^{2}$. Portanto, se de um lado a sociedade liga o aleitamento ao amor materno e a todos os benefícios que ele garante ao binômio, de outro a lactante pode se deparar com os reais sentimentos acerca da amamentação que em alguns casos, não condizem com pré-estabelecidos pela sociedade, e principalmente quando estas mulheres amamentam em cárcere privado.

A prática do Aleitamento Materno possui aspectos importantes, que compreende direitos de mãe e filho, da coletividade e da humanidade ${ }^{3}$.O direito à amamentação é inerente à mulher em qualquer circunstância, inclusive àquelas que estão em privação de liberdade. Para que esse direito seja garantido, existe a base jurídico-constitucional que valoriza a efetividade dessa ação, mesmo que a realidade se mostre incoerente quanto à garantia das especificidades acerca da digna amamentação no cárcere ${ }^{4}$.

No encarceramento feminino, aspectos inerentes à maternidade precisam ser avaliados, como a garantia da presença dos filhos junto às mães pelo período previsto por lei. Com o intuito de garantir condições favoráveis para a permanência dessas crianças no sistema prisional, foi publicada a Portaria Interministerial $n^{\circ} .210$, de 16 de Janeiro de 2014, que instituiu a Política Nacional de Atenção às Mulheres em Situação de Privação de Liberdade e Egressas do Sistema Prisional (PNAMPE). Esta ratifica, entre outras questões, que instituições risionais femininas sejam dotadas de local específico para gestante e arturiente, berçário (espaço destinado à permanência de lactentes com suas ăes, de modo a favorecer o aleitamento materno e creche para crianças maiores 
de 6 meses e menores de 7 anos que estejam desamparadas). Ainda, prevê o período mínimo de um ano e meio para convivência da mulher com seu filho e amamentação ${ }^{5}$.

Partindo desta perspectiva, o processo da amamentação no sistema prisional, requer uma atenção especial voltada às especificidades das mães privadas de liberdade, necessitando de ações multisetoriais que compreendam a importância do aleitamento materno, que é assegurado nas políticas sociais e de saúde.

Contudo, cabe destacar que o estudo da promoção da amamentação dentro do cárcere privado é um tema ainda pouco explorado e há pouca informação disponível sobre estudos centrados nos sentimentos das mães e o que elas têm vivenciado sobre amamentação dentro do sistema penitenciário.

Sendo assim, o objetivo do estudo é compreender os sentimentos das lactantes em situação prisional acerca da amamentação. Este estudo buscou responder a seguinte questão: Como mãe, quais os sentimentos de amamentar seu(a) filho(a) na prisão?

\section{Método}

Trata-se de uma investigação qualitativa de caráter exploratória e descritiva utilizando para análise dos dados a técnica de Análise de Conteúdo Temático ${ }^{6}$. O critério por saturação da amostra, que constitui uma ferramenta conceitual usualmente aplicada em pesquisas qualitativas no campo da saúde 7 .

Os sujeitos da pesquisa foram 08 lactantes maiores de 18 anos, pertencentes a população reclusa na Colônia Penal Feminina Bom Pastor (CPFBP), localizada no município de Recife-PE.

Como critério de seleção da Penitenciária Feminina, considerou-se o fato ser a única instituição do Estado dotada de estrutura física para acolher a mãe u bebê durante o período de lactação. 
As lactantes foram entrevistadas individualmente, no mês de outubro de 2014 a partir de instrumento semi-estruturado e todo diálogo foi integralmente gravado e transcrito na íntegra. A amostra dos dados deu-se pelo método de saturação. Assim, foram elencadas três categorias que emergiram dos discursos dos sujeitos sobre o tema em questão.

Para assegurar a condução ética no decorrer de todo processo desta pesquisa, os indivíduos que se dispuseram a participar tiveram as observâncias éticas respeitadas, conforme contempla a Resolução n 466, de dezembro de 2012 do Conselho Nacional de Saúde. O estudo obteve a anuência do município para a sua aplicação e foi aprovado pelo Comitê de Ética em Pesquisa do Centro Universitário Tabosa de Almeida ASCES-UNITA, sob o protocolo nº 94 806. Para garantir o anonimato, as entrevistadas estão codificadas por nomes de pedras preciosas.

\section{Resultados e Discussão}

Em relação ao perfil das mulheres que compuseram a amostra deste estudo, as mesmas encontram-se na faixa etária entre 21 e 32 anos, a grande maioria afirmava ser solteira e apenas 3 tinha uma união estável. Sobre a escolarização, 5 mães possuem Ensino Fundamental Incompleto. Com relação ao número de filhos, 4 das entrevistadas afirmaram ter dois filhos, 3 delas diziam ter entre três e quatro filhos, e 1 das mulheres mencionou ser mãe de cinco filhos. Quanto ao tempo de reclusão dessas mulheres, 1 das mães disse estar há oito meses na prisão, 3 delas afirmaram estar por volta de um ano e seis meses, outras 3 encontram-se privada de liberdade há mais de dois anos, e 1 delas há mais de três anos.

Nas falas analisadas, foram evidenciados alguns aspectos importantes bre a vida no cárcere e a relação entre o binômio mãe-filho a partir do ponto de ta das mães privadas de liberdade. No decorrer da análise temática dos dados, ergiram três categorias; Amamentação: meio de prevenção de doenças e de 
cumprimento do papel de mãe; Desmame precoce no ambiente prisional e processo de separação mãe e filho: dicotomia de sentimentos positivos e negativos e a Experiência do amamentar no ambiente prisional e sua correlação com o extramuros.

Amamentação: meio de prevenção de doenças e de cumprimento do papel de mãe

A amamentação exclusiva até os seis meses de idade e o reconhecimento da sua importância principalmente no que tange os aspectos biológicos da composição do leite materno e sua influência na saúde do lactente, estiverem presente na maioria das falas das mães entrevistadas, como visto nestas:

...previne muita coisa, muita doença, não só da mãe até pro bebê mesmo. (ÁGATHA)

...vi minha mãe dando de mamar a meus irmãos. (AMETISTA)

...Eu amamentei porque eu sei que ele precisa do leite materno. (ESMERALDA)

...o leite de peito éo melhor leite que tem, e tem que dar até 6 meses. (RUBI).

A partir dos discursos acima, é possível identificar fatores culturais transmitidos acerca da amamentação, sendo perceptível que as mulheres possuem conhecimento empírico no que se refere à importância nutricional do leite materno e sua efetividade na imunização da criança. Estas percepções convergem com as recomendações da Organização Mundial de Saúde (OMS), do Fundo das Nações Unidas para a Infância (UNICEF) e do Ministério da Saúde que defendem que a prática do Aleitamento Materno para a promoção da saúde desenvolvimento infantil satisfatório, necessita ser exclusivo até os 6 meses de da e complementado até os 2 anos ou mais ${ }^{8}$. 
Reforça-se ainda, que o leite materno diminui os números de diarreias, infecções respiratórias e alergias, preenchendo todas as necessidades que a criança precisa, é de mais fácil digestão e diminui sua resistência a agentes patogênicos, promovendo a maturidade do organismo. Ainda, crianças que possuem adequada amamentação, têm menos riscos de doenças, que consequentemente, leva à redução dos índices de uso de medicações e internações. Dessa forma, a interrupção precoce da amamentação leva a criança à exposição dos agentes infecciosos, causando danos à saúde 9 .

Ao passo que há tal reconhecimento para tais lactantes, para outras, o processo de amamentação além de conjugar oportunidade de nutrição, também se consolida como possibilidade para que a mulher desenvolva os atributos inerentes ao papel de mãe, seja sob forma de preceito traduzido no sentimento de obrigação em amamentar ou instintivamente, como maneira de compensação mútua entre o binômio.

A prática é vista como uma formação de vínculo entre mãe e bebê de maior relevância nessa fase, o toque e o olhar, fortalecem os laços afetivos, transmitindo segurança para o binômio mãe/bebê ${ }^{9}$, como é notório nas falas seguintes:

...tem que amamentar né. (DIAMANTE)

...aprendi a ser mãe dentro da cadeia, a única coisa que a cadeia me fez foi aprender a dar de mamar. (RUBI)

...tem que passar o mais amor possível e a amamentação proporciona isso. (QUARTZO)

...tenho prazer de ver ela se alimentando de mim. (CRISTAL) ...dar de mamar me possibilita dar muito amor a ela. (SAFIRA)

Com base nos relatos das mulheres, é perceptível a tomada de decisão em mentar e reconhecer os benefícios inerentes a amamentação, que é um fator sencial para a prestação de cuidados de Enfermagem nesse contexto, visto que 
a participação durante esse processo leva à diminuição da resistência à implementação da intervenção e a aprendizagem no contexto da amamentação.

Desmame precoce no ambiente prisional e processo de separação mãe e filho: dicotomia de sentimentos positivos e negativos

Entende-se que a ideia de afastamento do binômio mãe e filho após completos seis meses da criança, muitas vezes dá origem a fortes sentimentos de fragilidade e impotência. Pois, se de um lado a amamentação possibilita a criação do vínculo entre mãe e filho e o fortalecimento dos laços afetivos, de outro, amamentar no cárcere privado pode remeter a uma série de dificuldades, entre elas o sentimento negativo advindo do rompimento físico que repercutirá diretamente no estado emocional dessa mãe. Contudo, a intenção de minimizar o dissabor da separação é evidenciada através do desejo de desmame precoce:

...dói mesmo é lembrar que você tá dando de mamar e que um dia sua filha tá indo simbora... o ruimé só isso, saber vai ter que parar. (RUBI)

...até porque eu penso em tirar logo ela minha fia, porque eu sei que de uma hora pra ela vai e tem que tirar. (ÁGATHA)

Estar ciente que o convívio com o filho é diminuto, é que traz a mulher medo, tristeza, desmotivação, e inclinação a não continuidade do aleitamento como forma de exaurir-se de tais sentimentos, como expresso:

... a pessoa fica assim, muito triste por que ela vai ter que ir. (SAFIRA)

...amamentar conforta e ao mesmo tempo não...vai ter que sair de mim. (AMETISTA)

Destaca-se que diante dessa dicotomia entre mãe-filho, pode-se perceber ue o estado emocional da mulher se apresenta de forma negativa, podendo arretar efeitos adrenérgicos, levando à diminuição do reflexo de excreção do 
leite, não suprindo as necessidades nutricionais que a criança precisa e levando a um sentimento de impotência à mãe?

Entretanto, esses sentimentos que cingem a mulher oscila entre prazerosos e importunos, e quando indagadas, predominantemente os sentimentos de amor, prazer e carinho, são retratados por elas enquanto mães ao amamentar seus filhos, ainda que no ambiente prisional. Sendo o sentimento de amor o mais mencionado pelas mulheres acerca da amamentação:

...Sinto prazer, amor de tá amamentando. (DIAMANTE)

...eu sinto amor, muito amor, e dar de mamar me possibilita dar muito amor a ela. (SAFIRA)

...É a única coisa boa aqui dentro, resumo esse sentimento em amor. (CRISTAL)

...é uma forma pra gente poder demonstrar o amor que tem por eles. (QUARTZO)

... sinto um amor tão grande. (AMETISTA)

A experiência do amamentar no ambiente prisional e sua correlação com o extramuros

No tocante a vivencia no ambiente prisional, percebeu-se a partir da verbalização das entrevistadas frente ao paralelismo da vivencia anterior de amamentar, e agora no ambiente prisional, as mulheres acenaram dessemelhanças:

...aqui na unidade tem muita diferença, pra mim teve diferença, não sei explicar. (QUARTZO)

...Sei lá, é diferente... não tá em casa, é completamente diferente. (SAFIRA)

...dá nem pra sentir direito aqui nessa cadeia (pausa) ...é diferente... (pausa) não estou sabendo falar (risos). (ÁGATHA) 
Viu-se que tais mulheres expressam diferença em amamentar seus filhos em ambiente prisional sobreposto à experiência fora dali, no entanto, nas falas as mulheres não condensam esta expressão em sentimentos, apenas pontuam o fato de haver diferença. Pode-se extrair então, que a prisão traz à algumas mulheres indiferença e sentimento de pesar, onde o descontentamento é evidenciado nas falas de duas delas:

...É bom né, mas aqui dentro não. (ESMERALDA)

...Não é muito bom não ... a gente não se sente bem né? Porque a criança não tem nada haver com o erro da gente. (AMETISTA)

No entanto, para Rubi e Diamante, o fato de vivenciar a lactação na unidade prisional não causa interferências diretas neste processo quando comparada a vivência anterior.

...não muda nada não, do jeito que você dar de mamar lá fora você pode dar dentro da cadeia. (RUBI)

...independentemente de estar na prisão ou não. (DIAMANTE).

O apontamento da convivência familiar, a falta de suporte nos cuidados com o lactente e para o próprio manejo da amamentação também são pontuadas pelas mães:

...tive dificuldades, doía muito, chegou a ferir... [...]vontade era tá na rua com meu filho né? Poder tá amamentando meu filho junto do pai dele, cuidado do meu filho na rua né?. (AMETISTA)

...senti falta das pessoas que a gente gosta pra poder ajudar... ela teve cólica, que meus outros filhos, se tiveram foi com minha mãe junto, e eu não me apavorei como me apavorei ontem. (QUARTZO) 
...se fosse meu filho de primeira viagem, eu não sei nem o que é que seria, sem minha mãe, sem minha família por perto, como eu ia saber tanta coisa?. (CRISTAL)

Conforme os relatos das mulheres, o apoio da família, incentivo de amigos e estado emocional interferem diretamente na amamentação ${ }^{10}$. As mulheres entrevistas nesse estudo manifestaram a necessidade de outra pessoa para ajudar, esclarecer e acompanhar durante o período da amamentação. Então, os familiares e as pessoas próximas e significativas para as mulheres, são vistos como fontes de ajuda.

Percebe-se nesse contexto, que é o enfermeiro quem mais se relaciona com a mulher durante o pré-natal e pós-parto, tendo um importante papel nos programas de educação em saúde, e deve sempre preparar a gestante para o AM para que, quando essa prática ocorra, exista uma adaptação necessária e seja um período tranquilo, evitando assim, dúvidas, dificuldades e possíveis complicações durante a amamentação ${ }^{11}$.

Um estudo, reforça o quão o acompanhamento do pré-natal é importante, pois identificou que $86 \%$ das mães que aderiram ao pré-natal não tiveram complicações, e 13\% das grávidas tiveram complicação na gestação, tendo como causas sangramento, convulsão, infecção urinária, diabetes e hipertensão $\operatorname{arterial}^{12}$.

\section{Conclusões}

Inúmeros são os sentimentos vivenciados pelas lactantes quanto ao processo de amamentação no ambiente prisional, permeando os extremos de prazer e tristeza.

O fato de verbalizarem amor, está diretamente relacionado ao vinculo mãe filho, sendo que o sentimento de culpa, ou compensação é conseguinte ao de steza frente a separação da criança. 
Percebeu-se que a ausência das orientações dos profissionais de saúde, constituem outro tipo de apoio social que é crucial e também deve ser ofertado à lactante afim de minimizar os imbróglios ocasionados pela falta de assistência no que se refere aos cuidados pertencentes ao processo de aleitamento materno.

Além de encontrar-se a mercê de um sistema que por vezes é desestruturado e inapropriado à promoção do aleitamento materno, as lactantes do presente estudo constituem uma população que se percebe, onerada, exclusa, e que ao adentrar com seu filho na unidade prisional não exime seus mais variados sentimentos.

Portanto, é necessário que seja reprojetado o apoio ofertado ao binômio e que haja um aporte através de uma equipe multiprofissional efetivamente presente e sensível as especificidades que cada mulher apresenta, para que assim, este momento seja vivido realmente com o sentimento de amor e satisfação e afastado aqueles de pesar.

\section{Referências}

1. Santiago LB. Manual do Aleitamento Materno. Barueri, SP: Manole, 2013.

2. Ângelo BHB, Pontes CM, Leal LP, Gomes MS, Silva TA, Vasconcelos MGL. Breastfeeding support provided by grandmothers: an integrative review. Rev Bras Saude Mater Infantil. 2015 Abr- Jun 15 (2): 161-170.

3. Oliveira EF, Teixeira MC. O direito fundamental das presidiárias e seus filhos ao aleitamento materno. Rev Curso de Direito da Faculdade de Humanidades e Direito. 2014. 11(11): 68-101.

4. Soares EMC, Castro AED. Amamentação no cárcere: as entrelinhas para mães e filhos como sujeitos de Direito. Rev Âmbito Jurídico. 2012. 107(15):1-3.

Ministério da Justiça (BR) Portaria Interministerial $\mathrm{n}^{\circ}$. 210, de 16 de janeiro de 2014: institui a Política Nacional de Atenção às Mulheres em Situação de Privação Liberdade e Egressas do Sistema Prisional e dá outras providências. Diário icial da República Federativa do Brasil, 17 Jan 2014. Seção1. 
6. Bardin L. Análise de Conteúdo. 5ª ed. Lisboa: Edições 70; 2009.

7. Fontanella BJB, Ricas J, Turato ER. Amostragem por saturação em pesquisas qualitativas em saúde: contribuições teóricas. Cad. Saúde Pública. 2008 Jan 24(1):17-27.

8. Bomfim LTM, Novaes TF, Bonanato K, Navarro RS, Tedesco TK, Imparato JCP et al. Factors related to the practice of exclusive breastfeeding in different cities of the States Minas Gerais and Bahia, Brazil. Pesq Bras Odontoped Clin Integr. 2017. 17(1):1-10.

9. Moraes JT, Oliveira VAC, Alvin EAB, Cabral AA, Dias JB. A percepção da nutriz frente aos fatores que levam ao desmame precoce em uma unidade básica de saúde de Divinópolis/MG. R. Enferm. Cent. O. Min 2014 Jan/abr 4(1):971-982.

10. Viana RAA. Ferreira EG, Barboza MCC, Sampaio LMA. Aleitamento materno: desmistificando esse ato de amor como uma abordagem na promoção da saúde. Revista da ABENO. 2014. 14(1):38-46.

11. Mascarenhas ACL, Miranda LTT, Brasil GB, Moia LJMP, Pimentel IMS. A percepção das puérperas frente à atuação do enfermeiro na promoção do aleitamento materno em um hospital amigo da criança do estado do Pará. Revista Paraense de Medicina. 2015 Jul/Set 29(3):23-32.

12. Pereira DO, Ferreira TLS, Araújo DV, Melo KDF, Andrade FB. Avaliação das consultas de pré-natal: adesão do pré-natal e complicações na saúde maternoinfantil. Revista Ciência Plural. 2017; 3(3):2-15. 